\title{
A simulated bird gastric mill and its implications for fossil gastrolith authenticity
}

\author{
Oliver Wings
}

Steinmann-Institut für Geologie, Mineralogie und Paläontologie, Universität Bonn, Nussallee 8, 53115 Bonn, Germany. E-mail: oliver.wings@web.de Current address: Museum für Naturkunde Berlin, Invalidenstraße 43, 10115 Berlin, Germany.

Received 12 June 2008

Accepted 15 August 2008

Published 20 February 2009

\section{Key Words}

stomach stones

artificial gizzard

clast surface development

polish

gastrolith identification

\begin{abstract}
A rock tumbler, stones, water, plant material, hydrochloric acid, and pepsin were used to simulate a bird gizzard in order to study abrasion rate and influence of stomach juices and foodstuff on gastrolith surface development. The experiment lasted for six months. Each week, the "stomach" was supplied with fresh grass and stomach juices. After the end of the experiment, the set of stones had a combined weight loss of $22.4 \%$, with softer rock types showing higher abrasion rates. The combination of stomach juices and silica phytoliths within the grass had no visible effect on stone surface development: polish or pitting did not occur. A second experiment combined only pebbles with water in the tumbler. Results indicate that rock abrasion is mainly caused by contacts between moving stones. A comparison with authentic ostrich gastroliths showed that abrasion in the artificial stomach must have been lower than in a real gizzard, but still too high to maintain or develop surface polish. If high polish occasionally seen on sauropodomorph dinosaur gastroliths was indeed caused in a stomach environment, it implies digestive processes different from those of extant birds and the "artificial gizzard". Geologic origins of polish, such as transport in hyperconcentrated flows, wind blasting, or tectonic movements must be considered for polished fossil gastroliths and isolated clasts in fine-grained sediments (exoliths).
\end{abstract}

\section{Introduction}

Geo-gastroliths, swallowed stomach stones, occur in a variety of fossil and extant vertebrates including nonavian dinosaurs, crocodilians, and birds (Baker 1956; Whittle \& Everhart 2000; Wings 2004, 2007). When gastroliths are separated from skeletal remains, their unambiguous identification is extremely difficult. Occasionally polished, isolated clasts in fine-grained Mesozoic sediments should hence be called "exoliths" instead of "gastroliths" (Wings 2007). For gastrolith identification, it is important to understand and document surface alteration of stones in the digestive tract. Because of limited availability of suitable data and the resulting poor understanding of processes which influence pebbles in the gastric environment, new experiments and observations were conducted in real birds (Wings \& Sander 2007) and with the experimental design of an "artificial gizzard" presented here. The artificial gizzard experiment did not intend to exactly replicate all processes in the avian ventriculus, but was designed to test general chemical and mechanical con- trols on abrasion and polishing of gastroliths. The most influencing factors within the stomach environment are stomach fluids (acid and enzymes), amount of plant matter, and type and force of movement. Attention was paid to insure that the conditions of the experiment were approximating real stomach conditions. Especially the addition of acid and enzymes improved the authenticity of the simulation compared to previous experiments (Chatelain 1991; Moore 1998).

\section{Material and methods}

A rock tumbler was used as a simplified substitute of a gizzard (Fig. 1). The actual intended purpose of such tumblers is to polish semi-precious stones. The machine is built with a sealed rubber compartment and has relatively soft walls with longitudinal grooves. The rubber is a rather rough, but appropriate alternative for the gastric wall. The cylindrical rubber compartment can hold $700 \mathrm{~cm}^{3}$ which is close to the average volume of an ostrich gizzard: $868 \mathrm{~cm}^{3}$ (calculated from mass data given for gizzard contents in 135 German ostriches, Wings 2004). The compartment was continuously moved by a small electric motor, except during refilling times. 

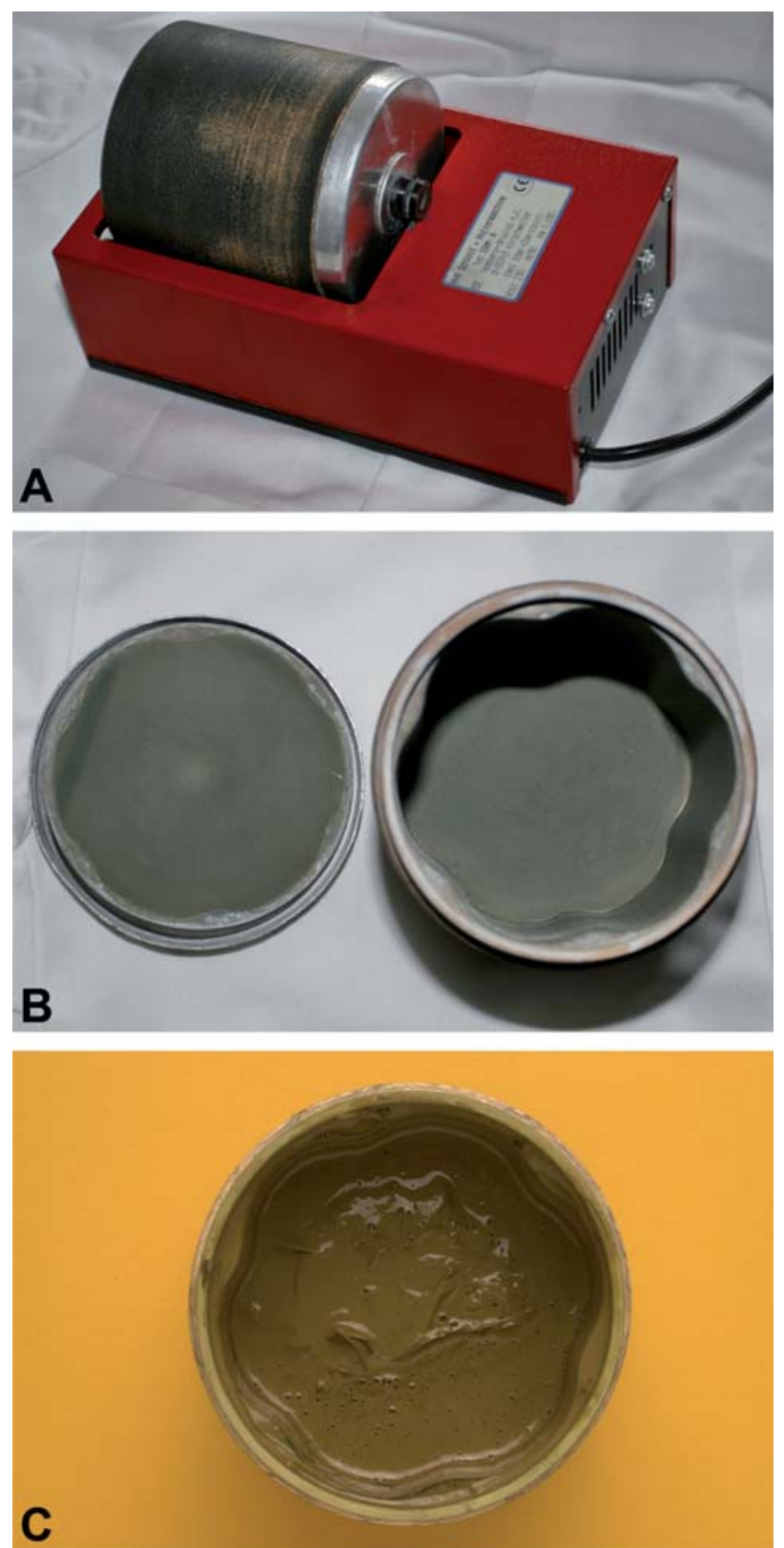

Figure 1. Rock tumbler ("artificial stomach") used for the experiments. A. Complete mounted machine; B. View into the empty rubber-lined drum, with rubber-coated cap on the left; C. View into the rubber-lined drum after seven weeks of operation and one week after the last addition of fresh ingredients. Plant matter is totally disintegrated due to mechanical and chemical treatment, resulting in a sludge in which the stones are embedded (not visible). Inner diameter of the drum: $10 \mathrm{~cm}$.

Fresh cut perennial rye grass (Lolium perenne) was used as plant material for the experiment because of its mechanical resistance, high contents of phytoliths, and its importance in the diet of free-range ostriches on German farms. Gastroliths of these German farm os- triches were used for comparison (Wings 2004; Wings \& Sander 2007). To facilitate and accelerate possible chemical effects on the gastroliths, hydrochloric acid $(\mathrm{HCl})$ and pepsin significantly higher in concentration than in gastric juices of birds (Duke 1986a; Ziswiler \& Farner 1972) were used for the simulated stomach juices. Freshly secreted gastric juice contains about $0.5 \% \mathrm{HCl}$ and has a $\mathrm{pH}$ around 2 (Duke 1986a; Schmidt-Nielsen 1997), but the normal pH in the stomach is slightly higher due to dilution by ingesta (Duke 1986a). In living animals, stomach juices are constantly secreted and replaced. In the experiment, stomach juices and "ingesta" were replaced once a week. During replacement, a fraction of the digested plant matter was discarded and exchanged for a constant amount of fresh ingredients. The $\mathrm{pH}$ fluctuated around 1 during the experiment.

The artificial stomach was set up in March 2001 and run continuously at room temperature for six months, because this period is more than sufficient to alternate shape and surface textures of bird gastroliths (Wings \& Sander 2007). Initially, the stomach was loaded with $113 \mathrm{~g}$ fresh-cut grass, $375 \mathrm{~g}$ stones, $3 \mathrm{~g}$ pepsin dissolved in $100 \mathrm{ml}$ tap water, and $25 \mathrm{ml}$ of $10 \% \mathrm{HCl}$. Each week, $20 \mathrm{~g}$ grass, $1 \mathrm{~g}$ pepsin in $5 \mathrm{ml}$ tap water, and $10 \mathrm{ml}$ of $10 \% \mathrm{HCl}$ were added. Different amounts of ingredients were used during three weeks in order to test if stomach juice concentration was adequate for the amount of plant matter processed and to determine the maximum amount of plant matter that could be digested in the artificial gizzard. In the 6th week, $50 \mathrm{~g}$ grass, $1.5 \mathrm{~g}$ pepsin in $5 \mathrm{ml}$ tap water, and $10 \mathrm{ml}$ of $10 \% \mathrm{HCl}$ were added. In the 7th week, $60 \mathrm{~g}$ grass, $3 \mathrm{~g}$ pepsin in $5 \mathrm{ml}$ tap water, and $30 \mathrm{ml}$ of $10 \% \mathrm{HCl}$ were added. In the 8 th week, no grass (the large amounts added in the two weeks before were not yet disintegrated), $1 \mathrm{~g}$ pepsin in $5 \mathrm{ml}$ tap water, and $10 \mathrm{ml}$ of $10 \% \mathrm{HCl}$ were added. In the following weeks the original amounts of ingredients ( $20 \mathrm{~g}$ grass, $1 \mathrm{~g}$ pepsin in $5 \mathrm{ml}$ tap water, and $10 \mathrm{ml}$ of $10 \% \mathrm{HCl}$ ) were added until the experiment was terminated.

The rock samples used in this experiment were small, randomly selected river pebbles from the Rhine River (mainly composed of vein quartz, quartzite, sandstone, lydite) (Fig. 2). These pebbles were chosen for comparability with ostrich (Struthio camelus Linnaeus, 1758) gastroliths from a farm in the region (Wings 2004; Wings \& Sander 2007). The farm ostriches graze on pastures situated on the Middle Pleistocene terrace of the Rhine River and have thus access to pebbles of identical composition. Additionally, several larger stones were selected purposefully. Three stones had artificial surfaces and shapes, respectively: two polished standard quartz samples (black and white), previously polished in a rock tumbler, as well as one rock-sawed granite cube with one polished face and an edge length of $2 \mathrm{~cm}$. Some cherts and silicified mudstones, respectively, also were added because such stones develop the highest luster among ostrich gastroliths (Wings, unpublished data). Rock type and size of all used pebbles was comparable to genuine ostrich gastroliths $(>80 \%$ of all ostrich gastroliths are siliceous, with a common size range of 2-20 mm, Wings 2004).

A second sequence of the experiment was conducted in order to investigate the influence of the tumbler rubber walls on pebble surface development. Similar pebbles were put in the tumbler together with tap water, but without stomach juices and plant matter, and also tumbled for six months. A third sequence of the experiment investigated if gastroliths alone increase digestive efficiency. During this preliminary experiment, the tumbler was loaded only with grass and pebbles and run for one week.

The pebbles were only examined at the end of the experiments because any sooner separation of gastroliths, plant matter, and stomach

Figure 2. Stones used in the artificial stomach before and after the experiment. A. Stones before the experiment. Several stones in the upper right possess a very high luster due to preexisting polishing, other stones exhibit sharp corners and edges; B. Same stones after the experiment. No high luster is preserved, all stones possess dull surfaces. Very few stones (black specimens in the center) show a slightly higher (resinous) luster compared to pictures before the experiment. All sharp edges are now rounded. Some pebbles are considerably smaller than before the experiment. 

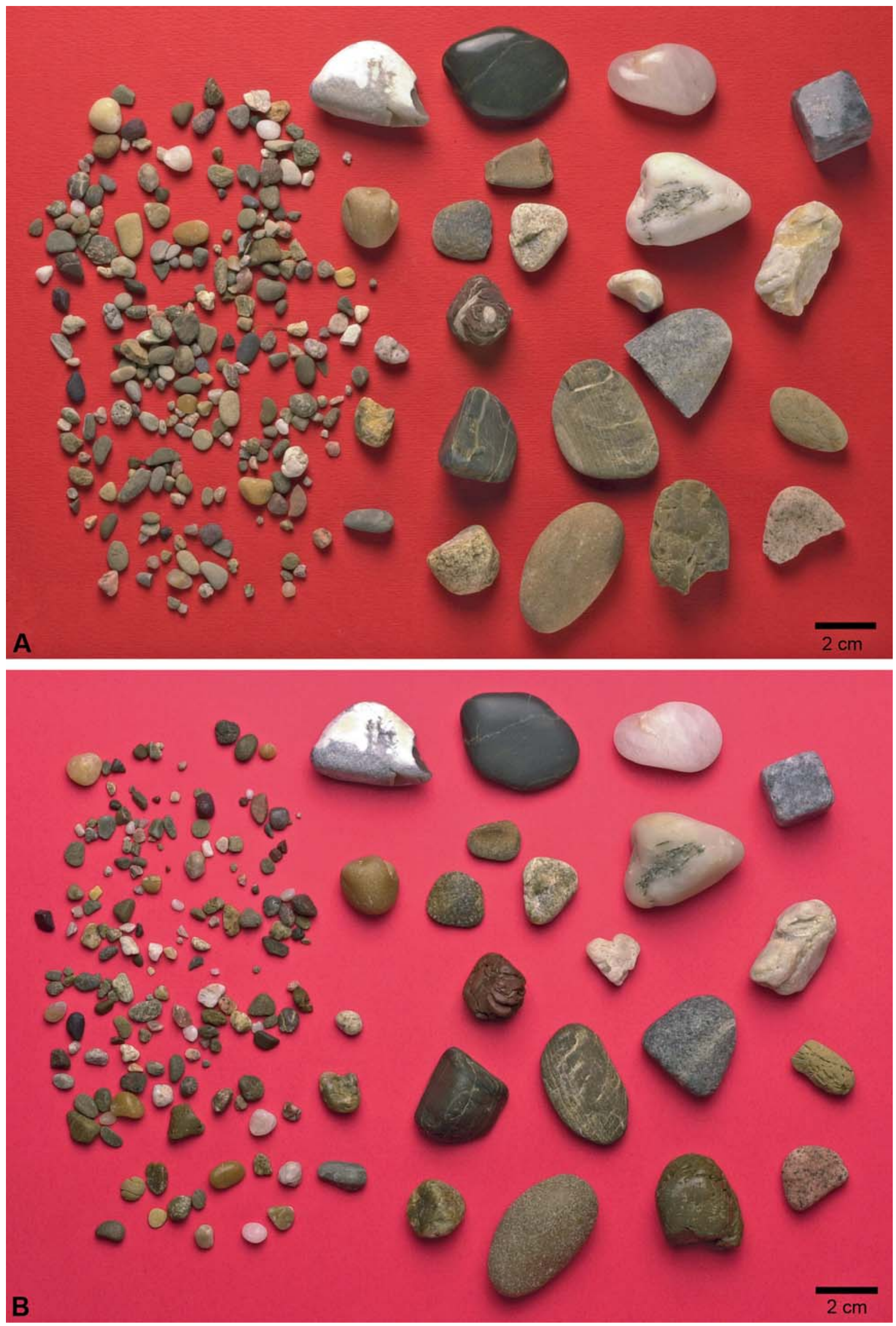


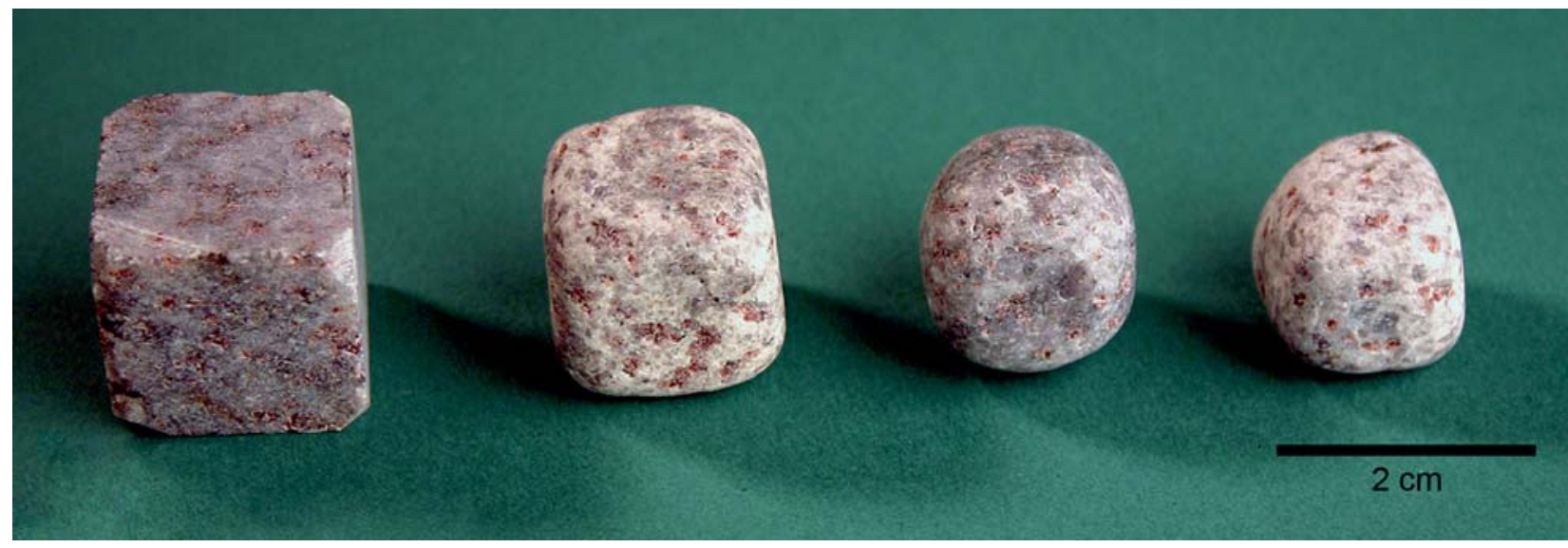

Figure 3. Rock-sawed cubes of the granite standard sample used in the experiment. The left stone is an original sample used for the tests (weight: $22.3 \mathrm{~g}$ ), the second stone from the left was moved for approximately 180 days in the artificial stomach (weight: $18.9 \mathrm{~g}$ ), the second from the right was moved for approximately 180 days in the tumbler filled only with water (weight: $12.2 \mathrm{~g}$ ), the stone on the right was retrieved from an ostrich gizzard after 50 days (weight: $10.7 \mathrm{~g}$ ). Note that the abrasion in the ostrich gizzard was higher than in other experiments, in spite of a shorter residence time. The lowest abrasion rate occurred in the artificial stomach.

juices would have caused major disturbance to the experimental setting. After the experiments, changes of surface texture of stones (river gravel, artificially polished stones, rock cubes) from both experiments were examined via close-up photography and stereo light microscopy. Ostrich gastroliths, including quartz samples which had a similar artificial polish before they were ingested by the ostriches, were used for comparison (Wings \& Sander 2007). Denotation of luster is based on commonly used terms of light reflection on mineral surfaces (Klein et al. 1993).

\section{Results}

In the environment of aggressive stomach juices and exposed to continuous grinding, the plant material was pulped and disintegrated within a few days after feeding. All stones in both experiments showed high mechanical erosion (Figs 2B, 3). However, the abrasion rate was considerably higher in the experiment without plant matter and stomach juices as evident from the granite sample (Fig. 3). The total weight of the stones after the artificial stomach experiment was $291.0 \mathrm{~g}$. This is a weight loss of $84 \mathrm{~g}$ (22.4\%). As expected, softer rock types such as sandstones show a generally higher abrasion rate than hard rock types such as vein quartz. All sharp edges of the stones were eroded. The standard granite cube sample in the artificial stomach experienced a weight loss of $3.4 \mathrm{~g}(15.3 \%)$. The identi-

Figure 4. Close-up photographs of standard quartz sample used in the experiments. A. An unaltered standard quartz sample in the polished state. Note the smooth surface and the high, vitreous luster; B. Standard quartz sample after six months in the artificial stomach. Note uniformly abraded surface without major scratches or pitting indicating constant, low energy abrasion; C. Similar standard quartz sample after 24 hours in an ostrich gizzard. Note deep scratches in the surface and absence of pitting. Scratches indicate powerful translational and lateral movements in the gizzard.
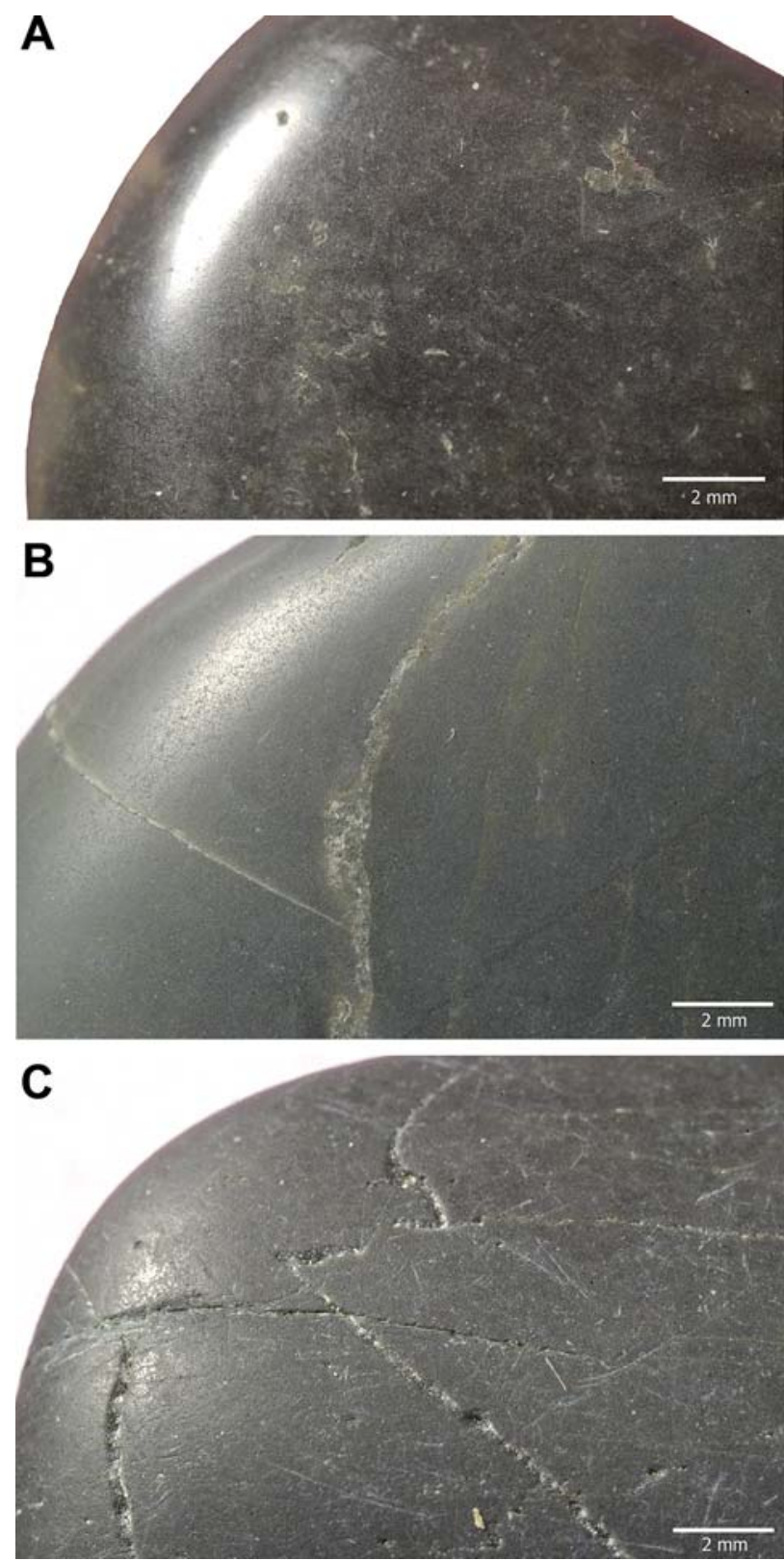
cal sample in the tumbler with water only, lost much more mass: $10.1 \mathrm{~g}(45.3 \%)$.

The artificially polished samples lost their luster in both experiments. In contrast, some of the chert and lydite samples, which initially had a dull surface, developed a glimmering resinous luster. The surface structures of stones of the same rock type show no differences between both six months experiments. While the original standard sample was highly polished (Fig. 4A) before the experiments, the sample from the artificial stomach shows equal abrasion without any major surface features such as scratches or pitting (Fig. 4B). Most of the polish is abraded. This is also a strong contrast to another polished standard sample which stayed for 24 hours in an ostrich gizzard and is heavily and irregularly scratched (Fig. 4C).

In the third, preliminary experiment using only grass and stones in the tumbler, stones were unable to triturate the grass but were instead enclosed in the ball formed by the plant material.

\section{Discussion and conclusions}

The three weeks change in regular additions of grass, acid, and enzymes to the artificial gizzard are considered to be of negligible influence regarding differing gastrolith abrasion and surface development, since availability and composition of food (and consequently of stomach juices) is usually fluctuating in living birds. The high amounts of grass $(50 \mathrm{~g}$ and $60 \mathrm{~g})$ given during two weeks were not completely digested and reveal the upper limit of plant matter which could be disintegrated. This indicates that amount and composition of stomach juices normally used in the experiment was adequate for the provided amount of "food". During the complete experiment, the enzymatic reaction of pepsin had no visible effect on the gastroliths, but supported the fast disintegration of plant matter by protein degradation. Likewise, the highly acidic environment $(\mathrm{pH}=1)$ had neither a positive nor a negative effect (i.e., preventing polish development) on the selected stones, but only would have caused the dissolution of existing limestones (Wings \& Sander 2007). Despite other reports (e.g., Brown 1941; Pandeli et al. 1999), stomach acid cannot chemically erode quartz or cause pitting on quartz gastrolith surfaces.

Moore (1998) and Moore et al. (1998) studied the effect of gastroliths on the breakdown of grass in geese gizzards. The artificial gizzard used in their experiments was modelled with two types of gizzard muscle morphology: asymmetric muscles generated a translational movement, whereas symmetric muscles generated a compressional movement (Moore et al. 1998). While the gizzard reconstruction of Moore et al. (1998) was mechanically more sophisticated than the experiment presented here, surface alteration of the stones used as gastroliths was not studied during the former experiments (Moore 1998).
The most significant difference between the new experimental setting and a bird gizzard is the type of movement. While a stone in a gizzard is subject to strongly fluctuating forces from defined directions [direct and lateral compression created by regular contraction pattern of two pairs of muscles (Duke 1986b; Ziswiler \& Farner 1972)], a stone in a rock tumbler is in constant movement, by uplift in the grooves of the rubber-lined drum and a short fall once the position in the groove becomes unstable. The total forces in the tumbler are thus probably much weaker and more equally distributed than in a gizzard. This is supported by the number and depth of scratches found during microscopic examination on the experimental "gastroliths". These scratches were produced by contacts between clasts and are generally smaller and less deep than on ostrich gastroliths (Fig. 4). The observation that rock abrasion was stronger in the experiment without plant matter indicates that the plant matter served as a buffer between the stones. Less contact between the stones slowed down the abrasion. In the preliminary experiment with only grass and stones in the tumbler, the stones did not triturate the grass at all. The efficiency of gastroliths in the gizzard is therefore directly correlated to the presence of gastric juices.

The largest fraction of polished pebbles in Mesozoic sediments interpreted as dinosaur gastroliths is represented by vein quartz (Stokes 1987; Wings 2004). This lithology did not develop any polish in the artificial stomach. Evidently, phytoliths do not enhance polish formation on gastrolith surfaces. Silica phytoliths are considerably softer (51-211 Vickers Hardness, HV; Sanson et al. 2007) than all quartz varieties (480-1260 HV; Taylor 1949) and thus do not contribute to surface wear of quartz clasts. The weak resinous luster formed on some cherts in the tumbler is similar to the luster found on shingle from chert beaches in Germany and England. This suggests that this luster is not a result of specific conditions in the gizzard but might rather be a result of abrasion of the specific microcrystalline structure of this quartz variety during contact between clasts.

Experimental research on gastrolith identification was conducted by Chatelain $(1991,1993)$ who used stream-abraded pebbles in tumbling experiments with conifer, cycad, and palm foliage as abrasive material. His preliminary analyses indicated that a highly polished, grid like pattern of fine scratches was imprinted upon originally dull surface textures. Unfortunately, no details of the experiments were given in these abstracts (Chatelain 1991, 1993), and the results of this work are not published elsewhere. In the light of the results presented here, it is not evident how tumbling with conifer and cycad foliage could have produced grid-like scratch patterns as reported by Chatelain (1991, 1993). There scratches may rather be the result of forceful contacts between gastroliths.

Preliminary implications for fossil gastrolith authenticity can be drawn from the experiment, and the findings have direct relevance for interpretation of dinosaur 
gastroliths. While surface polish has been used as the primary criterion for gastrolith identification in the past (Johnston et al. 1994; Manley 1993), this should be avoided since gastroliths from fossil and extant vertebrates are often dull (Wings \& Sander 2007). If gastrolith polish indeed formed inside the digestive tract of dinosaurs, this would have required very low abrasion rates atypical for extant herbivorous birds. Additionally, such conditions were not reproducible in the simulation despite the lower abrasion rate in the tumbler. Stomach juices and hard plant matter, including silica-rich material such as horsetail (Holzhüter et al. 2003), did certainly not play the key role in polish formation of sauropodomorph gastroliths.

However, preliminary results of the author's research on extant birds indicate that conifer foliage may indeed contribute to the development of highly polished surfaces on stones. Quartz grit found in the wild galliform bird Tetrao urogallus Linnaeus, 1758 (Western Capercaillie) often shows a relatively high, glistering sub-vitreous luster, whereas most other studied galliform and passeriform birds possess dull gastroliths similar to ostrich gastroliths (Wings, unpublished data). The higher polish on capercaillie gastroliths could be a result of specialized feeding habits: pine needles constitute up to $100 \%$ of its winter diet (De Juana 1994). Perhaps essential oils in conifer needles in combination with swallowed soil particles can trigger the development of gastrolith polish. Furthermore, conifer needles appear to be tougher than other foliage. They may give more resistance to gastroliths and diminish impacts between stones. If conifer (i.e., auracarian) needles contributed a major part to the diet of sauropodomorph dinosaurs as suggested by their high levels of energy available after prolonged fermentation (Hummel et al. 2008); and if the stones were subject to very limited abrasion for a long period, gastrolith polish may have formed in the digestive tract of sauropodomorphs. However, more research is needed to test this hypothesis.

Because many authentic sauropodomorph gastroliths (i.e., stones found in close association with bones) are not polished at all (Gillette 1994; Sanders et al. 2001; Wings 2004; Wings \& Sander 2007), other ways of polish formation than continuous movement in a gizzard must be considered for exoliths. In a normally functioning rock tumbler, polish is formed by movement of the stones in a liquid composed of very fine-grained abrasives and water. It is plausible that polish on many alleged dinosaur gastroliths was formed by somewhat similar geologic processes, such as hyperconcentrated flows (Zaleha \& Wiesemann 2005), wind polish (Dorr Jr 1966), or tectonic and diagenetic polishing similar to slickenside structures (Clifton 1965).

\section{Acknowledgements}

This paper is based on the author's doctoral thesis. Martin Sander (Bonn) is thanked for the steady support of the research. Georg
Oleschinski (Bonn) is acknowledged for his help taking photographs and Olaf Dülfer (Bonn) for taking care of the artificial stomach during the author's absence for field work. Reviews of Marcus Clauss (Zürich), David Gillette (Flagstaff), Daniela Schwarz-Wings (Berlin) as well as two anonymous reviewers contributed to the improvement of this manuscript. Financial support was received from the Graduiertenförderung Nordrhein-Westfalen and the Graduiertenkolleg "Evolution und Biodiversität in Raum und Zeit".

\section{References}

Baker, A. A. 1956. The swallowing of stones by animals. - The Victorian Naturalist 73 (6): 82-95.

Brown, B. 1941. The last dinosaurs. - Natural History 48: 290-295.

Chatelain, E. E. 1991. Surface textures on gastroliths as a key to origin: vertebrate gastric mills or stream abraded gravels. - Georgia Academy of Science, 68th annual meeting - Bulletin of the Georgia Academy of Science 49 (1): 35.

Chatelain, E. E. 1993. Surface textures produced by tumbling chert nodules derived from the Kaibab Formation (Permian) of Utah; characteristic of gastroliths or stream gravels? - Geological Society of America, Southeastern Section, 42nd annual meeting. Abstracts with programs 25 (4): 7.

Clifton, H. E. 1965. Tectonic polish of pebbles. - Journal of Sedimentary Research 35 (4): 867-873.

De Juana, E. 1994. Tetraonidae (grouse). In del Hoyo, J., Elliott, A \& Sargatal, J. (eds). Handbook of the Birds of the World. Vol. 2 New World Vultures to Guineafowl. Volume 2. Lynx Edicions, Barcelona: pp. 376-410.

Dorr Jr, J. A. 1966. Wind-polished stones: two similar sites. - Papers of the Michigan Academy of Science, Arts and Letters. Part 1, Natural Science 51: 265-273.

Duke, G. E. 1986a. Alimentary canal: secretion and digestion, special digestive functions, and absorption. In Sturkie, P. D. (ed.). Avian Physiology. Springer Verlag, New York: pp. 289-302.

Duke, G. E. 1986b. Alimentary canal: anatomy, regulation of feeding, and mobility. In Sturkie, P. D. (ed.). Avian Physiology. Springer Verlag, New York: pp. 269-288.

Gillette, D. D. 1994. Seismosaurus, the Earth Shaker. Columbia University Press, New York.

Holzhüter, G., Narayanan, K. \& Gerber, T. 2003. Structure of silica in Equisetum arvense. - Analytical and Bioanalytical Chemistry $376(4): 512-517$.

Hummel, J., Gee, C. T., Südekum, K.-H., Sander, P. M., Nogge, G. \& Clauss, M. 2008. In vitro digestibility of fern and gymnosperm foliage: implications for sauropod feeding ecology and diet selection. - Proceedings of the Royal Society B: Biological Sciences 275 (1638): 1015-1021.

Johnston, R. G., Lee, W. G. \& Grace, W. K. 1994. Identifying Moa gastroliths using a video light scattering instrument. - Journal of Paleontology 68 (1): 159-163.

Klein, C., Hurlbut, C. S. \& Dana, J. D. 1993. Manual of Mineralogy. Wiley, New York.

Linnaeus, C. 1758. Systema naturæ per regna tria naturæ, secundum classes, ordines, genera, species, cum characteribus, differentiis, synonymis, locis. Laurentius Salvius, Holmiæ.

Manley, K. 1993. Surface polish measurement from bona fide and suspected dinosaur gastroliths and wave and stream transported clasts. - Ichnos 2 (2): 167-169.

Moore, S. J. 1998. Use of an artificial gizzard to investigate the effect of grit on the breakdown of grass. - Journal of Zoology 246 119-124.

Moore, S. J., Lill, C. A. \& Sanson, G. D. 1998. Functional morphology of the gizzard of the domestic goose: design of an artificial gizzard. - Journal of Zoology 246: 111-117. 
Pandeli, E., Vannucchi, P. \& Monechi, S. 1999. Possible crystalline gastroliths of large marine Vertebrata from Oligocene pelitic sediments of the Northern Apennines, Italy: Reply. - Geology 27 (6): 576.

Sanders, F., Manley, K. \& Carpenter, K. 2001. Gastroliths from the Lower Cretaceous sauropod Cedarosaurus weiskopfae. In Tanke, D. H. \& Carpenter, K. (eds). Mesozoic Vertebrate Life: New Research Inspired by the Paleontology of Philip J. Currie. Indiana University Press, Bloomington \& Indianapolis: pp. 166-180.

Sanson, G. D., Kerr, S. A. \& Gross, K. A. 2007. Do silica phytoliths really wear mammalian teeth? - Journal of Archaeological Science 34 (4): 526-531.

Schmidt-Nielsen, K. 1997. Animal Physiology: Adaptation and Environment. Cambridge University Press, Cambridge.

Stokes, W. M. L. 1987. Dinosaur gastroliths revisited. - Journal of Paleontology 61 (6): 1242-1246.

Taylor, E. W. 1949. Correlation of the Mohs's Scale of Hardness with the Vickers's Hardness Numbers. - Mineralogical Magazine 28 (206): 718-721.

Whittle, C. H. \& Everhart, M. J. 2000. Apparent and implied evolutionary trends in lithophagic vertebrates from New Mexico and elsewhere. - New Mexico Museum of Natural History and Science Bulletin 17: 75-82.

Wings, O. 2004. Identification, distribution, and function of gastroliths in dinosaurs and extant birds with emphasis on ostriches (Struthio camelus). Published Doctoral Thesis, University of Bonn, Bonn: 187 pp. (Accessible online at http://nbn-resolving.de/ urn:nbn:de:hbz:5N-04626)

Wings, O. 2007. A review of gastrolith function with implications for fossil vertebrates and a revised classification. - Acta Palaeontologica Polonica 52 (1): 1-16.

Wings, O. \& Sander, P. M. 2007. No gastric mill in sauropod dinosaurs: new evidence from analysis of gastrolith mass and function in ostriches. - Proceedings of the Royal Society B: Biological Sciences 274 (1610): 635-640.

Zaleha, M. J. \& Wiesemann, S. A. 2005. Hyperconcentrated flows and gastroliths: sedimentology of diamictites and wackes of the upper Cloverly Formation, Lower Cretaceous, Wyoming, U.S.A. - Journal of Sedimentary Research 75 (1): 43-54.

Ziswiler, V. \& Farner, D. S. 1972. Digestion and the digestive system. In Farner, D. S. \& King, J. R. (eds). Avian Biology. Volume 2. Academic Press, London: pp. 343-430. 